\title{
Mechanism of imidazolium ionic liquids toxicity in Saccharomyces cerevisiae and rational engineering of a tolerant, xylose-fermenting strain
}

\author{
Quinn Dickinson', Scott Bottoms', Li Hinchman', Sean Mcllwain', Sheena Li², Chad L. Myers' ${ }^{3}$, Charles Boone ${ }^{4}$, \\ Joshua J. Coon ${ }^{1,5}$, Alexander Hebert ${ }^{1,5}$, Trey K. Sato ${ }^{1}$, Robert Landick ${ }^{1,6}$ and Jeff S. Piotrowski ${ }^{{ }^{*}}$
}

\begin{abstract}
Background: Imidazolium ionic liquids (IILs) underpin promising technologies that generate fermentable sugars from lignocellulose for future biorefineries. However, residual IILs are toxic to fermentative microbes such as Saccharomyces cerevisiae, making IIL-tolerance a key property for strain engineering. To enable rational engineering, we used chemical genomic profiling to understand the effects of IILs on S. cerevisiae.

Results: We found that IILs likely target mitochondria as their chemical genomic profiles closely resembled that of the mitochondrial membrane disrupting agent valinomycin. Further, several deletions of genes encoding mitochondrial proteins exhibited increased sensitivity to IIL. High-throughput chemical proteomics confirmed effects of IILs on mitochondrial protein levels. ILs induced abnormal mitochondrial morphology, as well as altered polarization of mitochondrial membrane potential similar to valinomycin. Deletion of the putative serine/threonine kinase PTK2 thought to activate the plasma-membrane proton efflux pump Pma1 p conferred a significant IIL-fitness advantage. Conversely, overexpression of PMA1 conferred sensitivity to IILs, suggesting that hydrogen ion efflux may be coupled to influx of the toxic imidazolium cation. PTK2 deletion conferred resistance to multiple IILs, including [EMIM]CI, [BMIM]Cl, and [EMIM]AC. An engineered, xylose-converting ptk2 $\triangle$ S. cerevisiae (Y133-IIL) strain consumed glucose and xylose faster and produced more ethanol in the presence of $1 \%[\mathrm{BMIM}] \mathrm{Cl}$ than the wild-type PTK2 strain. We propose a model of IIL toxicity and resistance.
\end{abstract}

Conclusions: This work demonstrates the utility of chemical genomics-guided biodesign for development of superior microbial biocatalysts for the ever-changing landscape of fermentation inhibitors.

Keywords: Chemical genomics, lonic liquids, Lignocellulosic, Biofuel, Biocatalysts

\section{Background}

Biomass-derived fuels and chemicals promise a suite of sustainable bioproducts from future lignocellulosic refineries. Before lignocellulose can be transformed to fuels or chemicals by microbes, however, cellulose and hemicellulose polymers must be converted to fermentable sugars by chemical deconstruction, enzymatic deconstruction, or a combination of both. These deconstruction methods

\footnotetext{
*Correspondence: jpiotrowski@wisc.edu

${ }^{1}$ DOE Great Lakes Bioenergy Research Center, University of Wisconsin-

Madison, Madison, WI 53726, USA

Full list of author information is available at the end of the article
}

typically generate hydrolysates with toxic small molecules that arise from residual deconstruction chemicals or biomass-derived inhibitors $[1,2]$ and slow fermentation rates at a substantial economic cost [3].

Lignocellulose- and deconstruction-derived inhibitors come in many forms, and the landscape of these inhibitors is continually changing as new pre-treatment, hydrolysis, and feedstocks technologies are developed [1]. These inhibitors include small acids, phenolics, and furans derived from hemicellulose or lignin and are ubiquitous challenges to bioconversion [2, 4]. However some of the most promising deconstruction methods 
rely on solvents like ionic liquids (IL) or $\gamma$-valerolactone $[5,6]$, which are partially retained in the hydrolysates and are not readily tolerated by fermentative microorganisms [7, 8].

Despite their toxicity, ILs hold special promise because they can be used either to solubilize crystalline cellulose for enzymatic hydrolysis $[9,10]$ or to support complete chemical deconstruction without the need for enzymes $[6,11]$. Among these ILs, imidazolium ionic liquids (IILs) (e.g. [EMIM]Cl, [BMIM]Cl, [EMIM]Ac) have been the best studied $[6,7,10]$. IILs used for lignocellulose deconstruction are salts composed of organic cation and inorganic anion that are liquids at near ambient temperatures. Adoption of IILs for lignocellulose biorefineries has been slowed by their expense; however, scale-up in production and routes to renewable ILs produced from lignin are likely to surmount this barrier $[9,11]$. Maximal recovery and recycling of IILs from lignocellulosic hydrolysates is generally deemed necessary to achieve economic feasibility. Despite a number of recovery efforts, however, IIL-derived hydrolysates can contain $\geq 1 \%$ residual IIL [8], which is problematic given IIL toxicity to fermentative microbes at $0.01 \%$ [ 7 , 8]. Increasing microbial tolerance of IILs is one strategy to lower the economic cost of IIL-based conversion processes.

The mechanism of IIL toxicity remains unknown in yeast and bacteria. A recent study found that IILs induced a shift from respiration to fermentation in yeast, suggesting they may affect central metabolism or mitochondrial processes [12]. Further, this toxicity could be synergistic in effects with other inhibitors and end-products like ethanol. Defining the mechanisms of IIL toxicity in microbes and identifying gene targets are prerequisites for engineering IIL-tolerant microbes for use in future lignocellulosic biorefineries.

There are several potential routes to create tolerant microbes, including screening natural genetic diversity in strains [13] and directed evolution [14], but these approaches do not necessarily provide enabling knowledge about the mechanisms of tolerance that could be used to engineer the microbes used in specific applications. Chemical genomics offers a third route to tolerant micobes, which is rapid and can be informative about mechanism [15]. This reverse-genetics technique leverages genome-wide mutant collections that can be challenged with a compound, and the fitness of individual mutants assess in a massively parallel way using mutantspecific molecular barcodes [16, 17]. Identification of sets of mutants with specific sensitivities can then give insight into the mechanisms of toxicity. Conversely, resistant mutants can identify points of engineering for tolerance in other genetic backgrounds.
In this report, we describe a chemical genomics approach (Fig. 1) to discover the genome-wide response to IILs toxicity and define their mode of toxicity. Using this information, we identified specific genes that mediate toxicity, identified a mode-of-action of IIL toxicity, and engineered an IIL-tolerant, xylose-fermenting strain of Saccharomyces cerevisiae by deleting an ion

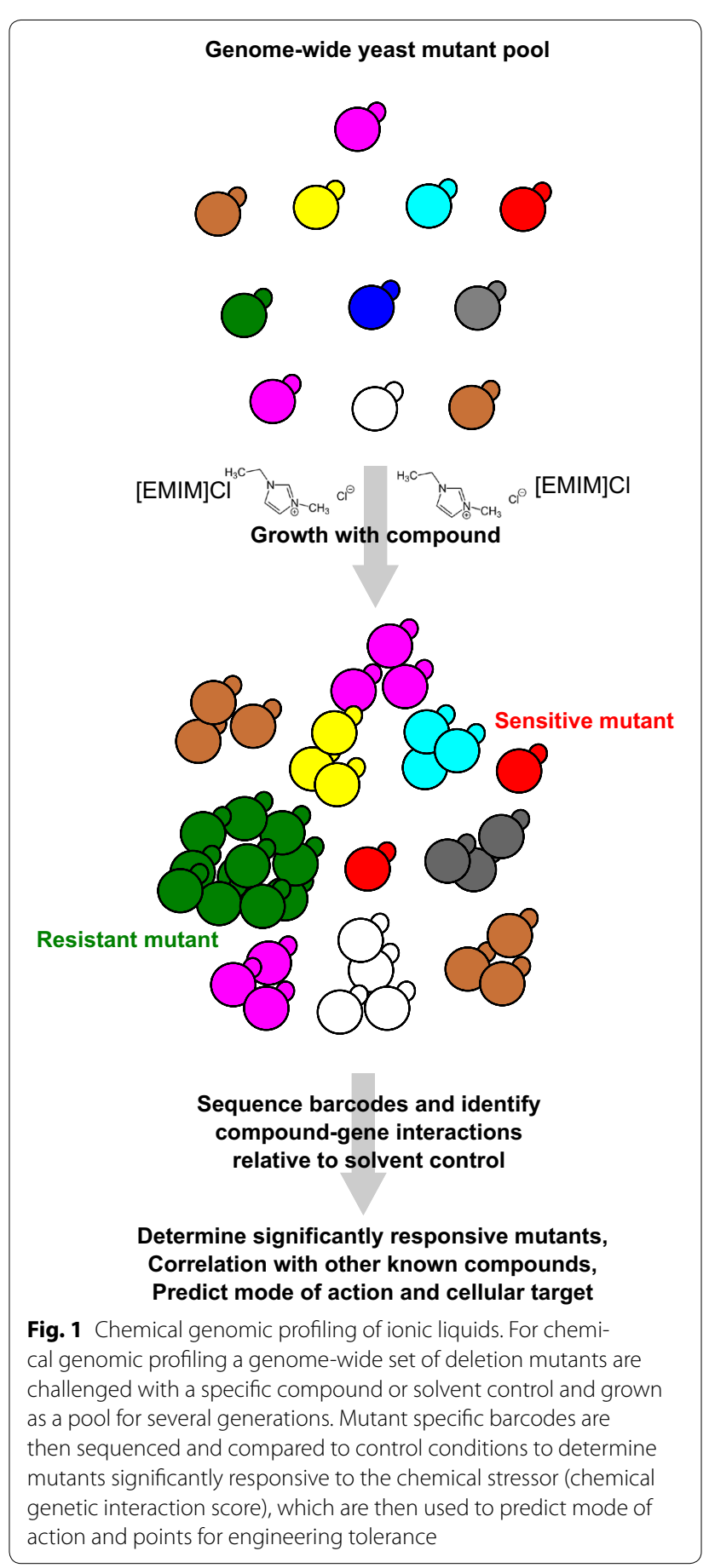


homeostasis regulatory gene. Our results illustrate a general approach for rapidly tailoring existing strains to tolerate specific chemical stressors encountered during industrial bioconversion.

\section{Methods}

Compounds, initial screening, and $\mathbf{I} C_{50}$ determination Compounds tested were purchased from Sigma (St Louis, MO). Cells of $S$. cerevisiae (MAT $\alpha$ pdr1 $1::$ natMX

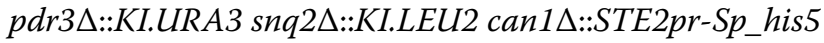
lyp $1 \Delta$ his $3 \Delta 1$ leu $2 \Delta 0$ ura $3 \Delta 0$ met15 $\Delta 0$ ), referred to as control strain, were grown in 96-well microtiter plates with $200 \mu \mathrm{L}$ cultures at $30^{\circ} \mathrm{C}$ in YPD $(10 \mu \mathrm{g} / \mathrm{mL}$ in yeast extract $(10 \mathrm{~g} / \mathrm{L})$ peptone $(20 \mathrm{~g} / \mathrm{L})$ medium with $1 \% \mathrm{glu}$ cose), with a drug or dimethyl sulfoxide (DMSO) control. Cell densities of individual cultures were measured by optical density at $600 \mathrm{~nm}\left(\mathrm{OD}_{600}\right)$ using a TECAN M1000 over a $48 \mathrm{~h}$ growth period. The specific growth rate was calculated using GCAT analysis software (https://gcat3pub.glbrc.org/) [13]. When presented, $\mathrm{IC}_{50}$ values for growth inhibition were calculated from triplicate eight point dose curves and SigmaPlot 12.0. When presented, error bars are Mean \pm Standard error of at least three replicates.

\section{Chemical genomic analysis}

Chemical genomic analysis of [EMIM]Cl was performed as described previously $[17,18]$. The tested yeast deletion collection had 4194 strains using the genetic background described in Andrusiak (2012) [19]. We screened [EMIM] Cl at a concentration of YPD. $200 \mu \mathrm{L}$ cultures of the pooled, deletion collection of $S$. cerevisiae deletion mutants were grown with [EMIM]Cl or a DMSO control in triplicate for $48 \mathrm{~h}$ at $30{ }^{\circ} \mathrm{C}$. Genomic DNA was extracted using the Epicentre MasterPure ${ }^{\mathrm{TM}}$ Yeast DNA purification kit. Mutant-specific molecular barcodes were amplified with specially designed multiplex primers [20]. The barcodes were sequenced using an Illumina HiSeq 2500 in Rapid Run mode. Three replicates of each condition ([EMIM]Cl vs DMSO) were sequenced. The barcode counts for each yeast deletion mutant in the presence of [EMIM]Cl were normalized against the DMSO control conditions to define sensitivity or resistance of individual strains. To determine a $\mathrm{p}$ value for each top sensitive and resistant mutant, we used the EdgeR package [21, 22]. Data was visualized in Spotfire 5.5.0 (TIBCO, USA). A Bonferroni-corrected hypergeometric distribution test was used to search for significant enrichment of GO terms among the top 20 sensitive deletion mutants [23].

\section{Proteomic analysis of [EMIM]Cl treated cells}

For yeast proteomics, triplicate $10 \mathrm{~mL}$ of YPD $+0.25 \%$ [EMIM]Cl or YPD were inoculated with the control strain to a starting $\mathrm{OD}_{600}$ of 0.01 and incubated at $30{ }^{\circ} \mathrm{C}$ with shaking at $200 \mathrm{rpm} .2 \mathrm{~mL}$ of each culture was harvested when they reached an $\mathrm{OD}_{600}$ of $\sim 0.5$ (mid log phase growth). Cells were pelleted at $10,000 \mathrm{rpm}$, the media removed, and stored at $-80{ }^{\circ} \mathrm{C}$ until processing for proteome analysis.

Yeast cell pellets were resuspended in $6 \mathrm{M} \mathrm{GnHCl}$ (Sigma, St. Louis, MO) with $50 \mathrm{mM}$ tris pH 8.0 (Sigma, St. Louis, MO), boiled for $5 \mathrm{~min}$, and precipitated by adding methanol (Thermo Fisher Scientific, Pittsburgh, PA) to a final concentration of $90 \%$. The precipitate was centrifuged at 10,000 rcf for $5 \mathrm{~min}$, decanted, and air dried. The protein pellet was resuspended in $8 \mathrm{M}$ urea (Sigma, St. Louis, MO) with $100 \mathrm{mM}$ Tris $\mathrm{pH} 8.0,10 \mathrm{mM}$ tris (2-carboxyethyl) phosphine (Sigma, St. Louis, MO), and $40 \mathrm{mM}$ chloroacetamide (Sigma, St. Louis, MO). The resuspended sample was diluted to $1.5 \mathrm{M}$ urea with $50 \mathrm{mM}$ Tris $\mathrm{pH}$ 8.0. Trypsin was added to a final ratio of 1:20 (enzyme to protein) and the samples were incubated at ambient temperature overnight. Peptides were desalted over Strata-X cartridges (Phenomenex, Torrance, $C A$ ). Desalted peptides were dried in a speed vac and resuspended in $0.2 \%$ formic acid (Thermo Fisher Scientific, Rockford, IL). Peptides were quantified with the Pierce quantitative colorimetric peptide assay kit (Thermo Fisher Scientific, Rockford, IL).

For each analysis, $2 \mu \mathrm{g}$ of peptides were separated across a $30 \mathrm{~cm}, 75 \mu \mathrm{m}$ i.d. column packed with $1.7 \mu \mathrm{m}$ BEH C18 particles (Waters, Milford, MA). Mobile phase A was $0.2 \%$ formic acid and B was $0.2 \%$ formic acid, $70 \% \mathrm{ACN}$, and $5 \%$ DMSO (Thermo Fisher Scientific, Pittsburgh, PA). The gradient was $5-50 \%$ B over $100 \mathrm{~min}$ followed by a $100 \% \mathrm{~B}$ wash and re-equilibration with $0 \%$ B. Eluted peptides were analyzed on a Thermo Fusion Orbitrap (Thermo Fisher Scientific, San Jose, CA). Orbitrap survey scans were performed at 60,000 resolution, followed by ion-trap $\mathrm{ms} / \mathrm{ms}$ analyses of the most intense precursors (with $\mathrm{z}=2-6$ ) for less than $3 \mathrm{~s}$ and using a dynamic exclusion of $15 \mathrm{~s}$. The maximum injection time for each $\mathrm{ms} / \mathrm{ms}$ was $25 \mathrm{~ms}$ and the ion-trap resolution was set to turbo.

Peptides were identified and quantified from the MS data using the MaxQuant software suite with the Andromeda and MaxLFQ search and quantitation algorithms, respectively. Spectra were searched against a Uniprot human proteome and common contaminant database concatenated with the reverse sequences. Match between runs was toggled on with the default settings. Peptide and protein identifications were filtered to $1 \%$ FDR, and proteins were quantified by the MaxLFQ algorithm using the default settings. Data was visualized in Spotfire 5.5.0 (TIBCO, USA). A Bonferroni-corrected hypergeometric distribution test was used to search for 
significant enrichment of GO terms among the top 15 sensitive/resistant deletion mutants with a $p$ value of $\mathrm{p}<0.01[23]$.

\section{Agar diffusion assay}

YPD and YP-Glycerol (2 \%) agar plates were inoculated with one OD of control strain cells grown overnight. These were then allowed to dry before removing four $0.5 \mathrm{~cm}$ diameter plugs from the plates. $50 \mu \mathrm{L}$ of a $100 \mathrm{mg} / \mathrm{mL}$ solution of [EMIM]Cl in $\mathrm{ddH} 2 \mathrm{O}$ was then placed into each hole and allowed to diffuse until the hole was dry. The plates were then grown for $24 \mathrm{~h}$ at $30{ }^{\circ} \mathrm{C}$. A $1 \%$ agar, $2 \%$ carbon source, $1 \%$ Triphenyl tetrazolium chloride (TTC) overlay was then placed over the cells and allowed to grow for $24 \mathrm{~h}$ for visualization.

\section{Microscopy of yeast mitochondria}

Mid-log cultures of the control strain were used to inoculate a dose cure of [EMIM]Cl (0-1\%), and grown over night at $30{ }^{\circ} \mathrm{C}$. After $18 \mathrm{~h}$, the cultures were washed with $1 \mathrm{X}$ PBS and stained with SYTO18 (10 mM in HEPES; Life Technologies, USA). Cells were visualized fluorescence and GFP filter set. Photos were processed in Adobe Photoshop CC (Adobe, USA).

\section{Determination of mitochondrial membrane potential}

To determine changes in mitochondrial membrane potential induced by ILs, we used FACS analysis of $\mathrm{DiOC}_{6}(3)$ treated cells. $2 \mu \mathrm{L}$ of log phase cells of the control yeast were added to $200 \mu \mathrm{L}$ YPD with $0.25 \%$ [EMIM]Cl, $200 \mu \mathrm{g} / \mathrm{mL}$ valinomycin, $170 \mu \mathrm{M}$ antimycin a, $10 \mu \mathrm{g} / \mathrm{ml}$ benomyl, or solvent controls (water/DMSO) in triplicate. The cells were incubated for $4 \mathrm{~h}$ at $30{ }^{\circ} \mathrm{C}$, pelleted at $3000 \mathrm{rpm}$, and the supernatant removed. Pellets were suspended in $10 \mathrm{mM}$ HEPES buffer $+5 \%$ glucose (pH 7.4) with $200 \mathrm{nM}$ of $\mathrm{DiOC}_{6}(3)$ (Life Technologies, Carlsbad, CA, USA), and incubated at RT for $30 \mathrm{~min}$. Cells were diluted with HEPES buffer to appropriate density for FACS analysis. Green fluorescence of cells was quantified using a Guava EasyCyte (EMD Millipore, Billerica, MA, USA), and analysis GuavaExpress Pro software.

\section{Deletion of genes}

To delete PTK2 in Y133, we amplified the PTK2 deletion cassette from the yeast knock out collection using flanking primers designed from published deletion primer sequences [24]. Following PCR clean up, we transformed the PCR product into Y133, and selected resistant colonies on YPD + G418 agar. We confirmed the deletion of PTK2 by PCR using the confirmation primers described in [24].

\section{Overexpression of $P M A 1$}

We used the MoBY-ORF 2.0 version of PMA1 expressed via a $2 \mu$ plasmids under its native promoter [25]. Y133 was transformed with either pPMA1 or a blank vector via high-efficiency transformation protocol [26], and successful transformants were identified on YPD + G418 agar medium. IIL sensitivity tests of the overexpression mutant were performed using an 8-point dose curve in YPD + G418 medium on a TECAN M1000 plate reader (TECAN, USA).

\section{Determining $\mathrm{pH}$ effects}

To determine the effects of $\mathrm{pH}$ on [EMIM]Cl toxicity, triplicate wells of $198 \mu \mathrm{L}$ of YPD medium at $\mathrm{pH} 6.5$ or $\mathrm{pH}$ 5.0 (adjusted with $1 \mathrm{~N} \mathrm{HCl}$ ) $\pm 1 \%$ [EMIM]Cl was incoculated with $2 \mu \mathrm{L}$ of $\log$ phase cells of either Y133 or Y133IIL and were grown for $48 \mathrm{~h}$ at $30^{\circ} \mathrm{C}$ in a TECAN M1000 with growth measured every $15 \mathrm{~min}$.

\section{Growth and sugar conversion experiments}

To test the effects of [EMIM] Cl on fermentation, three $25 \mathrm{~mL}$ flasks were prepared with a YPXD (2\% glucose $/ 2 \%$ xylose) $+1 \%$ [EMIM]Cl, and three with only YPXD. Flasks were inoculated with rinsed Y133 or Y133 $p t k 2 \Delta$ cells to bring the initial $\mathrm{OD}_{600}$ to approximately 0.1 . The flasks were grown aerobically for $72 \mathrm{~h}$ with agitation at $30^{\circ} \mathrm{C} .1 \mathrm{~mL}$ samples were taken every $24 \mathrm{~h}$. Initial and daily samples were measured for $\mathrm{OD}_{600}$ and submitted for HPLC analysis to quantify sugar consumption and ethanol production. To test the effects of [BMIM] $\mathrm{Cl}$, twelve $25 \mathrm{~mL}$ anaerobic flasks and $1210 \mathrm{~mL}$ aerobic tubes were prepared with a YPXD (2 \% glucose/2\% xylose $)+1 \%$ [BMIM]Cl. Six tubes and six flasks were brought to a $\mathrm{pH}$ of 6.5 and the remainder were brought to a $\mathrm{pH}$ of five with $\mathrm{HCl}$. For each condition, (aerobic, $\mathrm{pH}$ 5 and 6.5, anaerobic pH 5 and 6.5) three flasks or tubes were inoculated with rinsed Y133 or Y133 $p t k 2 \Delta$ cells to bring the initial $\mathrm{OD}_{600}$ to approximately 0.1 . One replicate of the Y133, anaerobic, pH 6.5 was lost for the $72 \mathrm{~h}$ sample point because of contamination. The tubes were grown for $72 \mathrm{~h}$ with agitation aerobically at $30{ }^{\circ} \mathrm{C}$ while the flasks were grown anaerobically for $72 \mathrm{~h}$ with agitation at $30^{\circ} \mathrm{C} .1 \mathrm{~mL}$ samples were taken every $24 \mathrm{~h}$. Initial and daily samples were measured for OD and submitted for HPLC analysis to quantify sugar consumption and ethanol production.

\section{Results}

Chemical genomics predicts [EMIM]Cl affects mitochondria To identify targets of the IIL [EMIM]Cl, we undertook chemical genomic profiling using a panel of $>4000$ yeast non-essential gene deletion strains (Fig. 2a). Our screen identified 220 gene deletion mutants that were 
a

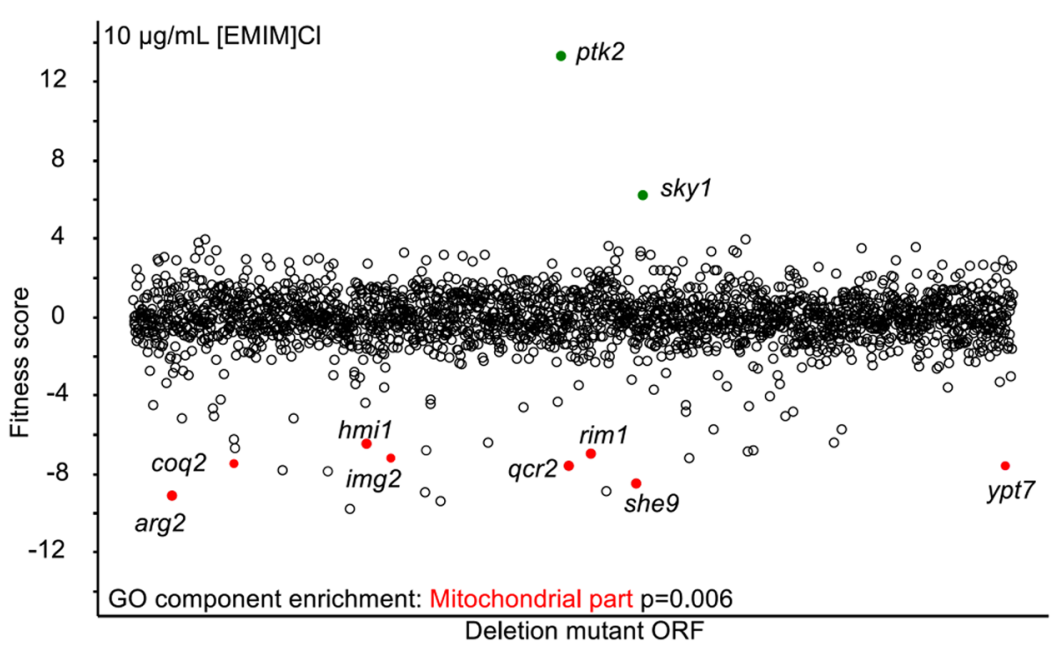

b

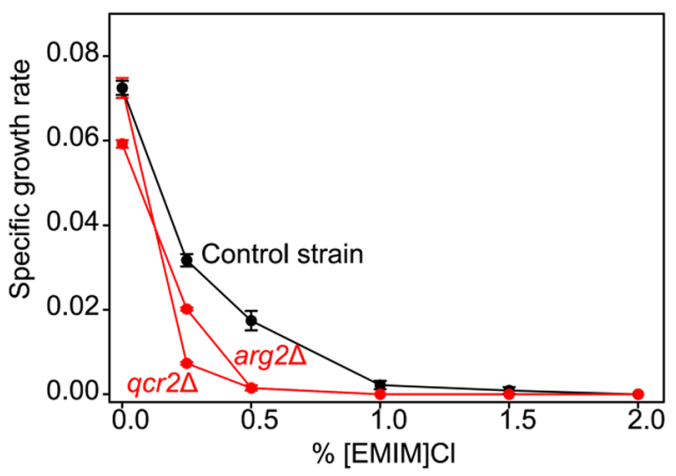

c
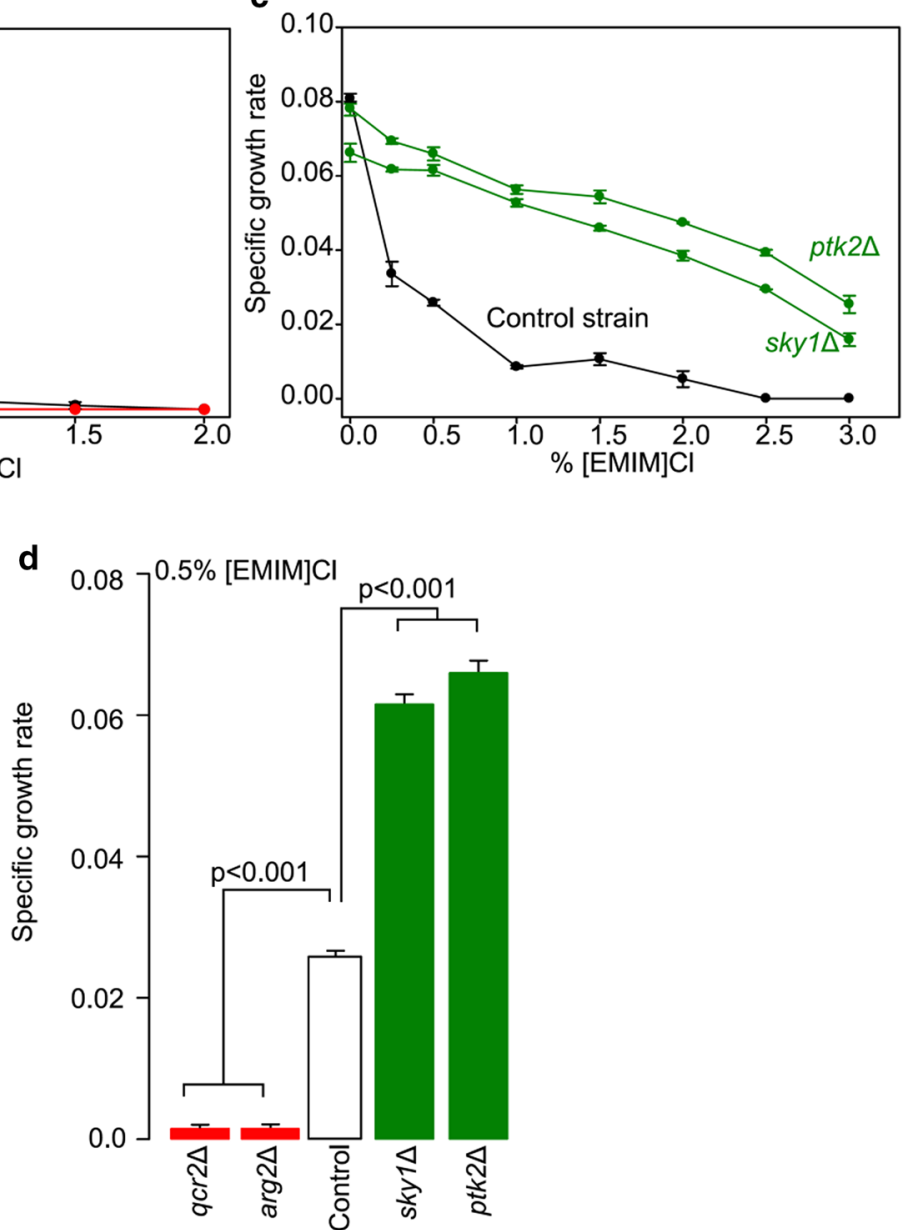

Fig. 2 Chemical genomic profiling of [EMIM]CI reveals mitochondrial genes are highly sensitive. Of the top 20 most significantly sensitive deletion mutants grown aerobically in YPD with $10 \mu \mathrm{g} / \mathrm{mL}$ [EMIM]Cl, eight were annotated to the mitochondrion (a). We tested the individual sensitivities of the top two most significantly sensitive and resistant mutants compared to the control strain $(\mathbf{b}, \mathbf{c})$ using an eight point dose curve. Mutants of ARG2 and QCR2 had significantly lower growth in $0.5 \%$ [EMIM] Cl compared to the WT, whereas mutants of PTK2 and SKY1 grew significantly better (d). $(n=3$, Mean \pm S.E $)$ 
significantly responsive to [EMIM]Cl $(10 \mu \mathrm{g} / \mathrm{mL})$ (Additional file 1). Among the top 20 sensitive mutants, we found gene ontology $(\mathrm{GO})$ enrichment $(\mathrm{p}<0.01)$ for genes that encode mitochondrial proteins (e.g. ARG2, COQ2, HMI1, IMG2, QCR2, RIM1, SHE9, YPT7); thus, [EMIM]Cl may affect mitochondrial function (Fig. 2a). We individually examined the growth of the two topranked sensitive mutants (QCR2, ARG2) and confirmed that each displayed significantly greater $(\mathrm{p}<0.01)$ sensitivity to [EMIM]Cl relative to the control strain (Fig. 2b, d).

Resistant mutants uncovered by chemical genomics can identify targets for rational engineering of resistance. The top resistant deletion mutant was PTK2, a putative serine/threonine protein kinase involved in regulation of ion transport across the plasma membrane, particularly polyamine cations $[27,28]$. This mutant had a 12 -fold increased $\left(\mathrm{p}=1 \mathrm{e}^{-74}\right)$ fitness in the presence of [EMIM] $\mathrm{Cl}$, indicating greater growth than all other strains. The second most significant resistant strain was a deletion mutant of SKY1 (fold change $=4.5, \mathrm{p}=1 \mathrm{e}^{-21}$ ), which is functionally similar to PTK2 and is a protein kinase that also regulates proteins involved in cation homeostasis and polyamine cation uptake [27, 29]. We confirmed the resistance of these gene deletions individually, and the PTK2 and SKY1 deletions exhibited significantly $(\mathrm{p}<0.01)$ higher [EMIM]Cl tolerance than the control strain (Fig. 2c, d). Finally, we correlated the chemical genomic profile of [EMIM]Cl to existing chemical genomic datasets [17] and found that it highly correlated with valinomycin $(\mathrm{p}<0.001)$, a neutral ionophore that collapses $\mathrm{K}^{+}$gradients across the mitochondrial membrane [30]; however, previous genome-wide studies have not shown that deletion of PTK2 or SKY1 confer significant resistance to valinomycin [17], which suggests $[\mathrm{EMIM}] \mathrm{Cl}$ has a different mechanism of action.

\section{Chemical proteomics confirms toxic effects of IILs on mitochondria}

These chemical genomics data, as well as pervious reports [12], suggest that [EMIM]Cl may be toxic to mitochondria. As a validation, we next tested the yeast proteome response of the strain to [EMIM]Cl treatment. We grew cells to mid-log with or without $0.25 \%$ [EMIM] $\mathrm{Cl}$ and then measured the levels of cellular proteins using high-throughput quantitative proteomics [31]. We found that among 729 proteins that changed levels significantly $(\mathrm{p}<0.01)$ in response to the IIL (Additional file 2), many mitochondrial proteins were significantly decreased in concentration compared to untreated cells $(\mathrm{p}<0.005$; Fig. 3). Among these were two proteins involved in mitochondrial citrate transport (Ctp1p, Ymh2p) and two mitochondrial ribosome proteins (Mrps35p, Rsm24).

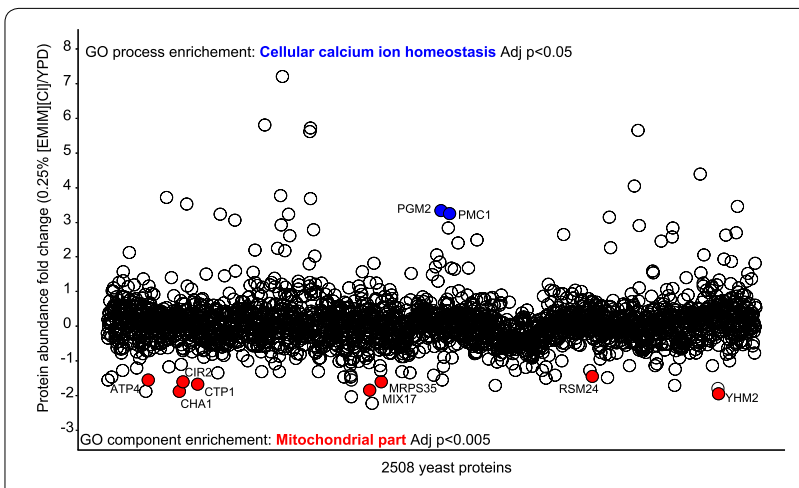

Fig. 3 [EMIM]Cl treatment affects mitochondrial protein levels. Protein abundance and identity of yeast grown in the presence of [EMIM]Cl normalized against a solvent control demonstrates of the top 20 most depleted proteins, eight were annotated to the mitochondrial part. Among the most significantly $(p<0.01)$ more abundant proteins in the presence of [EMIM]Cl, two were specifically involved in calcium ion homeostasis (blue). $(n=3)$

Among top proteins with increased abundance, we observed enrichment for proteins involved in small molecule catabolism $(\mathrm{p}<0.001)$ driven by Thi20p, Pgm2p, Car2p, Xks1p, Uga2p and Gad1p. More specifically, we observed enrichment $(p<0.05)$ for two proteins involved in calcium ion homeostasis (Pgm2p and Pmc1p). Taken together with the sensitive deletion mutants discovered in the chemical genomic profile, these data suggest IILs are toxic to the mitochondria, and specifically ion transport across the mitochondrial membrane.

\section{[EMIM]Cl disrupts mitochondrial membrane potential}

If IILs were toxic to mitochondria, their effects would be expected to be enhanced during aerobic growth on nonfermentable substrates, which requires mitochondrialdependent respiration. We found that IILs were indeed more toxic during cell growth on glycerol, which requires respiration, compared to growth on glucose, which does not (Fig. 4a).

Using microscopy, we next explored the effect of IILs on mitochondria. Cultures treated with [EMIM] $\mathrm{Cl}$ displayed a dose-dependent effect on mitochondrial structure, as determined with the stain SYTO18, which preferentially binds yeast mitochondrial nucleic acids (Fig. 4b). Untreated cells exhibited normal, tubular mitochondrial morphology; whereas at high doses, discrete morphology disappears, and the SYTO18 signal appeared diffused through the cell, suggesting a breakdown of mitochondrial integrity and release of mitochondrial nucleic acids. Finally, we used FACS analysis with the fluorescence stain $\operatorname{DiOC}_{6}(3)$, which accumulates in the mitochondrial membrane as a function of membrane potential. With a 4-h treatment, the known 
a

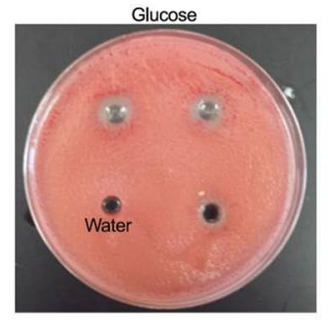

Glycerol

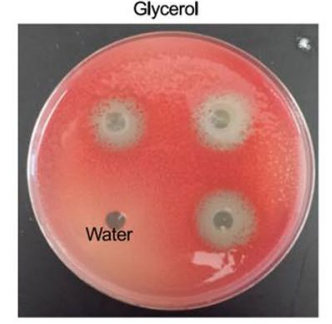

C

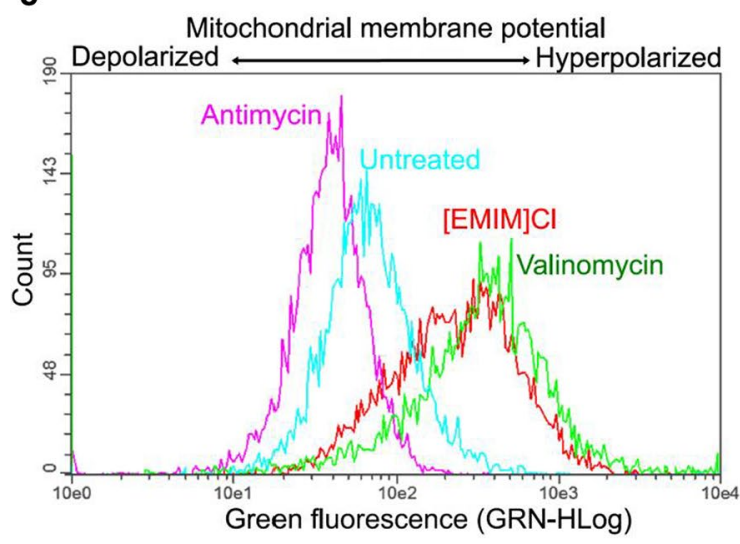

b
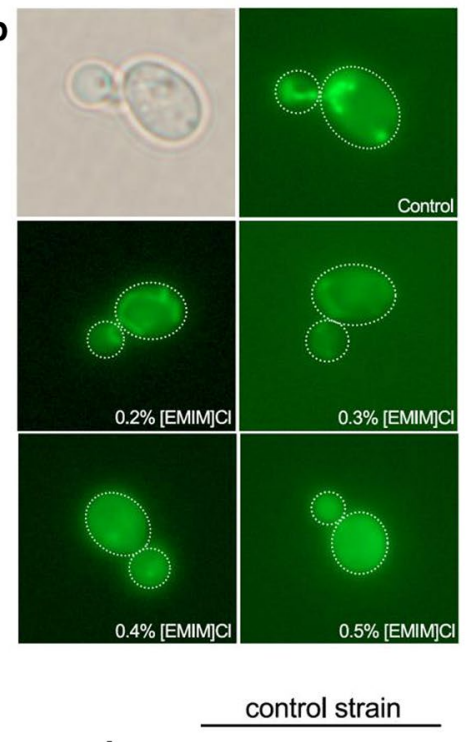

d

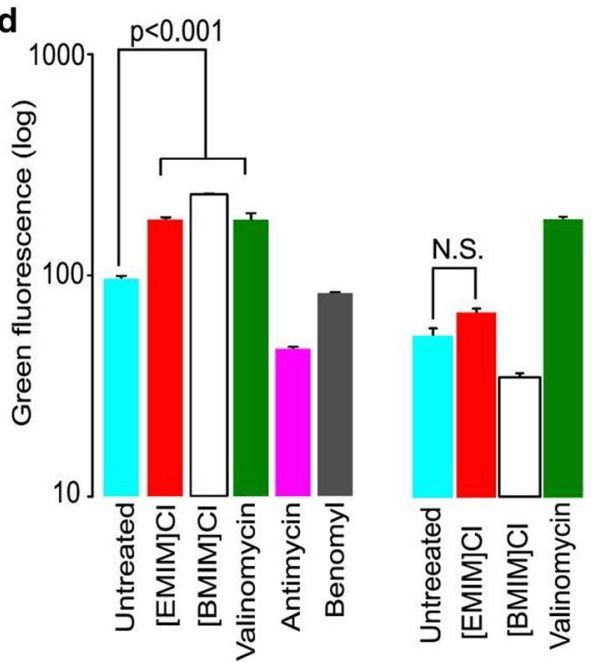

Fig. 4 Effects of [EMIM]Cl on respiration, mitochondrial structure, and membrane potential. Zones of inhibition caused by [EMIM]Cl on yeast grown on either glycerol or glucose (a). Dose dependent disappearance of yeast mitochondrial structure (tubular structures stained with SYTO18) in the presence of [EMIM]Cl (b). [EMIM]Cl treatment at sub lethal doses (0.25\%) causes increases DiOC $_{6}(3)$ fluorescence, as does the ionophore valinomycin $(\mathbf{c}, \mathbf{d})$. The uncoupling agent antimycin is included as a positive control, and the tubulin poison benomyl is included as an inhibitor with a mode of action unrelated to the mitochondrion. $\mathrm{DiOC}_{6}(3)$ fluorescence of the PTK2 mutant when treated with [EMIM]Cl, $[\mathrm{BMIM}] \mathrm{Cl}$, valinomycin or control (d)

ionophore valinomycin caused hyperpolarization of the mitochondrial membrane, whereas the membrane potential uncoupler antimycin resulted in depolarization relative to the DMSO-only control (Fig. 4c, d). With [EMIM] $\mathrm{Cl}$ treatment, we observed a significantly $(\mathrm{p}<0.01)$ increased fluorescence shift of $\operatorname{DiOC}_{6}(3)$, indicating a hyperpolarized mitochondrial membrane potential and thus greater dye uptake, similar to valinomycin (Fig. 4c, d). The tubulin poison benomyl was included as control agent that causes cell death through a mechanism unrelated to the mitochondria, as expected this compound did not alter membrane potential. Mitochondrial hyperpolarization can lead to ROS production and ultimately apoptosis in yeast [32]. Although mitochondria are not required for sugar fermentation to ethanol, they are required for fatty acid biosynthesis and other essential growth processes during anaerobiosis [33]. We found that the effect of [EMIM]Cl, but not valinomycin, on mitochondrial membrane hyperpolarization was alleviated in the PTK2 deletion mutant (Fig. 4d). This result suggests that influx of [EMIM]Cl is different than that of valinomycin, and possibly that the PTK2 deletion mutant 
decreases uptake of toxic $[\mathrm{EMIM}]^{+}$cation, similar to how uptake of other cations (e.g. spermine, tetramethylammonium) is reduced by the PTK2 deletion.

\section{Engineering IIL tolerance through an understanding of toxicity}

Our findings suggest that IIL affects mitochondrial function, and that deletion mutations known to decrease cation influx can increase IIL tolerance. We identified two kinase regulators whose deletion decreases IIL toxicity, PTK2 and SKY1. The products of both genes are known to enhance spermine uptake. As both spermine and IILs are weak bases, the role of PTK2 and SKY1 in IIL uptake may be similar to that in polyamine cation uptake. Spermine is transported by TPO1, 2, 3, and 4 in yeast, however none of these gene mutants were significantly responsive to [EMIM]Cl (Additional files 1,2), which suggest IILs may have a different transporter regulated by PTK2.

As $p t k 2 \Delta$ was the most resistant mutant in both the initial screen and the validation tests, we focused on this gene for engineering. PTK2 and SKY1 have a well-documented negative genetic interaction (deletion of both genes has a synergistic, negative effect on cell fitness) [34, $35]$, which would potentially throttle conversion rates in IIL produced hydrolysates. Further, the IIL tolerance of the PTK2 mutant alone was substantially higher $(>2 \%$ [EMIM]Cl) than levels of residual IILs that are found in IIL produced hydrolysates [8]. For these reasons, we chose not to delete both genes.

For conversion of lignocellulose to fuels and useful chemicals by $S$. cerevisiae, xylose-conversion remains a key challenge. Strains have been engineered and evolved for robust xylose fermentation [14, 36, 37], but their use to convert IIL-derived hydrolysates has not been reported. To test whether IIL-tolerance traits identified using lab strains can be used to engineer industrially relevant strains, we deleted PTK2 in a isolate of S. cerevisiae engineered for xylose-fermentation (Y133) [14]. The halfmaximal growth inhibition $\left(\mathrm{IC}_{50}\right.$ ) of [EMIM]Cl in $\mathrm{Y} 133$ yeast was $0.76 \%$, whereas the $\mathrm{Y} 133 p t k 2 \Delta$ mutant (hereforth called Y133-IIL) had an $\mathrm{IC}_{50}$ of $2.4 \%$ [EMIM]Cl (Fig. 5a). This improved tolerance was less dramatic than we observed in the control strain, but was still well above the amounts of IIL that would be expected in IIL hydrolysates. Importantly, this modification similarly conferred tolerance to other IILs, [BMIM]Cl and [EMIM]Ac (Fig. 5b, c), suggesting that toxicity of most or all IILs can be reduced by deletion of $P T K 2$.

$P T K 2$ is known to activate the essential proton efflux pump Pma1p by phosphorylation [38]. We found increased expression of PMA1 caused a significant decrease in $[\mathrm{EMIM}] \mathrm{Cl}$ tolerance (Fig. $5 \mathrm{~d}, \mathrm{p}<0.01$ ).

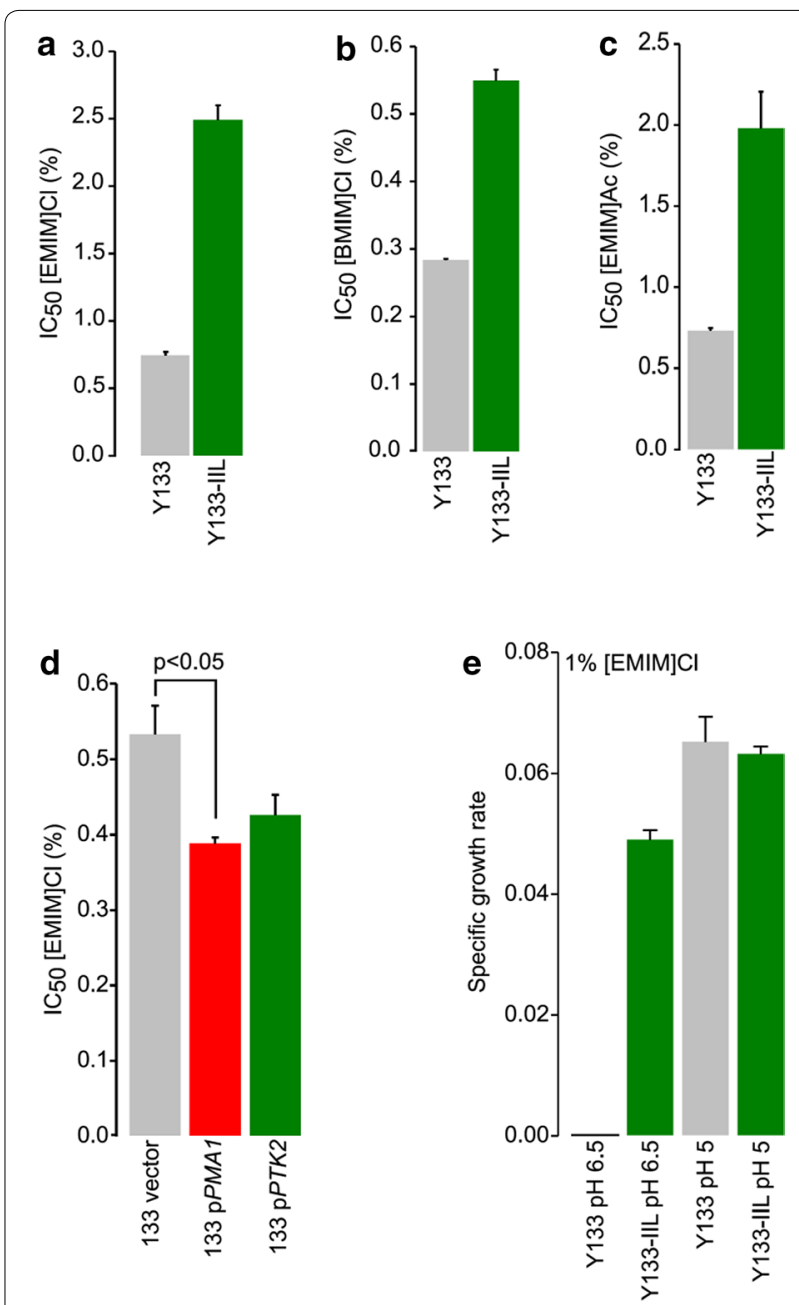

Fig. 5 The effect of IILs on cell growth in the background strain (Y133) or PTK2 mutant (Y133-IIL). IC $C_{50}$ values were determined for each xylose fermenting yeast strain grown in YPD containing various concentrations of [EMIM]Cl (a), [BMIM]Cl (b), or [EMIM]AC (c). In (d), Y133 was transformed with the indicated plasmids, and effects on $I C_{50}$ for [EMIM]Cl using the resulting transformants were assessed. To examine $\mathrm{pH}$ dependence on IIL toxicity, specific growth rates of the Y133 and Y133-IIL strains cultured in YPD media containing $1 \%$ [EMIM]Cl at pH 5 or $6.5(\mathbf{e})$. Mean \pm S.E

Overexpression of PTK2 also reduced [EMIM]Cl tolerance, but not significantly. This suggests that proton efflux by Pma1p may be coupled with influx of the toxic IIL cation, and that decreasing the activity of Pmalp by deletion of PTK2 can confer resistance to IILs. Interestingly, we observed a strong $\mathrm{pH}$ effect on IIL toxicity. At near neutral $\mathrm{pH}$ ( $\mathrm{pH}$ 6.5), growth inhibition by [EMIM]Cl was greater towards Y133, whereas there was not a significant difference in growth between Y133 and the Y133IIL at a lower $\mathrm{pH}$ ( $\mathrm{pH}$ 5.0) (Fig. 5e), perhaps because the lower $\mathrm{pH}$ decreases proton efflux by mass action. Uptake of polyamine cations like spermine are highly $\mathrm{pH}$ 
dependent; their uptake increases at higher $\mathrm{pH}$ [39] and IILs may be subject to a similar effect.

\section{Fermentative performance of IIL tolerant yeast}

The fermentative capacity of the engineered, IIL-tolerant yeast versus the parent strain is the best test of the chemical genomics-guided biodesign. Y133-IIL had greater growth and sugar conversion in the presence of $1 \%$ [EMIM]Cl than the background strain under aerobic conditions at $\mathrm{pH} 6.5$ (Fig. 6). We further tested the effects of both $\mathrm{pH}$ and oxygen on the performance of Y133 and Y133-IIL (Fig. 7a-d, Additional file 3). Because Y133-IIL exhibited cross resistance to all three IILs tested, we chose to assess fermentation performance in the presence of [BMIM]Cl, the most toxic IIL and one of particular interest for its lignocellulose deconstruction properties [11]. The greatest IIL toxicity occurs near neutral $\mathrm{pH}$ under aerobic conditions in the WT strain, where the Y133-IIL strain converted significantly more glucose and xylose to ethanol (Fig. 7b-d). At pH 5.0, the differences between the two strains were less dramatic, but the Y133-IIL strain still converted significantly more xylose to ethanol (Fig. 7c, d, p < 0.05), even under anaerobic conditions. Of note, in the absence of [BMIM]Cl, Y133-IIL performed equivalently to Y133 (if not slightly worse in some conditions) in terms of sugar conversion (Additional file 4); thus, the PTK2 deletion alone has no generally positive effect on growth, but confers a specific advantage in the presence of IILs. Although IIL toxicity can be alleviated at reduced $\mathrm{pH}$ and in anaerobic conditions, the PTK2 modification still confers an advantage that results in greater ethanol production.

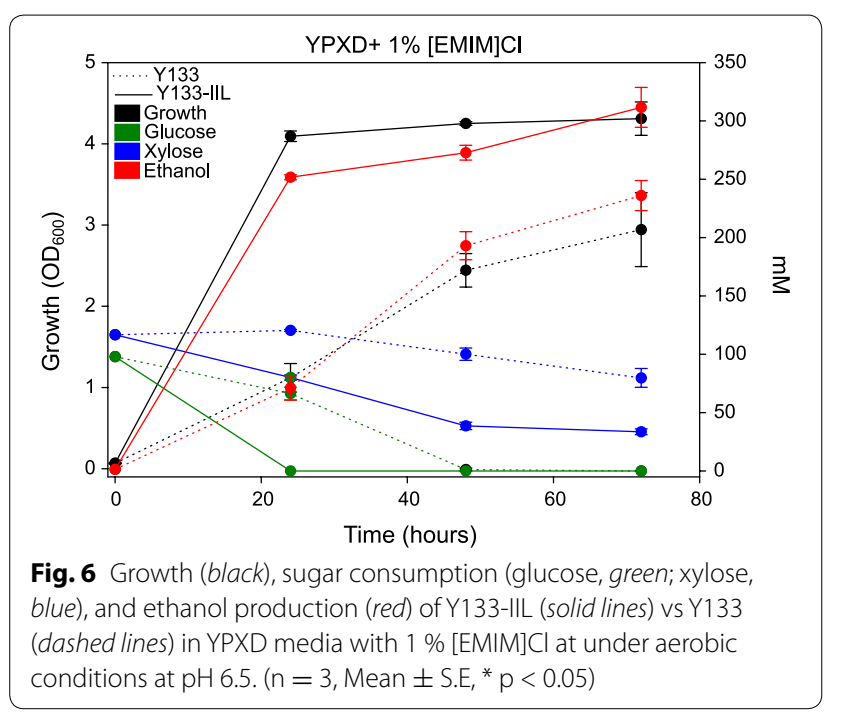

\section{A proposed mechanism of IIL toxicity and tolerance}

Based on these results, we propose the following model for IIL toxicity in yeast and its modulation by oxygen level and extracellular $\mathrm{pH}$ (Fig. 8). IILs induce increased proton efflux via Pmalp (activated by PTK2), which is coupled with import of the toxic imidazolium cation, similar to the role of PTK2 in uptake of the polycation spermine $[28,29]$. Once inside the cell, the IIL cation interacts with mitochondria leading to hyperpolarization of the mitochondrial membrane [32]. Decreasing proton efflux by deletion of PTK2 lessens accumulation of the IIL cation in cells and hence its interaction with mitochondria. The exact target of the imidazolium cation remains unclear. It may bind a specific mitochondrial enzyme or insert into the mitochondrial membrane to affect function of membrane-associated enzymes, leading to altered membrane potential. Regardless of the target, we predict this toxic effect will be more acute during aerobic respiration (Fig. 8, top half of each panel), which requires mitochondrial activity. ILL toxicity is increased at a higher $\mathrm{pH}$ (Fig. 8 top panel) because cation uptake is greater, similar to what has been observed for spermine transport [39]. When PTK2 is deleted, activation of Pma1p is reduced, leading to less proton efflux and less transport of the toxic imidazolium cation into the cell (Fig. 8, right).

\section{Discussion}

Using chemical genomic and proteomic profiling, we identified a potential mechanism for toxicity of imidazolium ILs in yeast. These agents damage mitochondrial function, apparently by inducing hyperpolarization of the mitochondrial membrane. In yeast, hyperpolarization of the mitochondrial membrane can ultimately lead to ROS production and apoptosis [32]. Future studies using GFP-fused mitochondrial proteins will be useful in determining the effect of IILs on specific proteins and gaining better resolution of mitochondrial morphological changes that occur upon exposure to IILs. IIL accumulation appears to differ from that of the $\mathrm{K}^{+}$ionophore valinomycin, as IIL-induced hyperpolarization can be alleviated by deletion of the kinase regulator of ion homeostasis $P T K 2$, whereas $p t k 2 \Delta$ has no effect on valinomycin-mediated hyperpolarization (Fig. 4d). This result is consistent with Pmalp-coupled influx of the IIL cation; valinomycin is a neutral molecule and its intercellular accumulation would not be stimulated by proton efflux. Our model posits an IIL-specific transporter, but further work will be required to identify the transporter. IIL toxicity can be lessened at lower $\mathrm{pH}$. Further, as toxicity appears to result from impaired mitochondrial function, growth under strict anaerobic conditions also lessens IIL toxicity. Nonetheless, mitochondrial function remains essential for cell viability even under strict anaerobic 


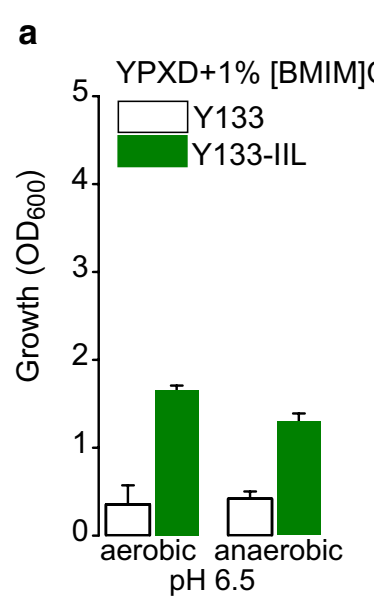

C

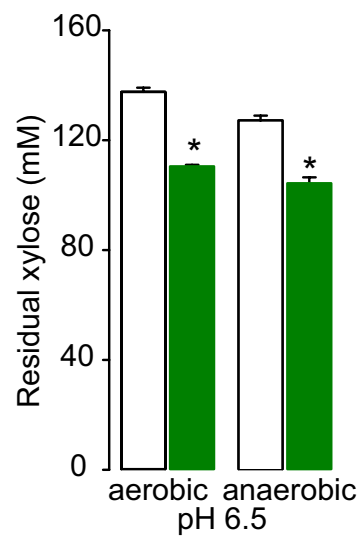

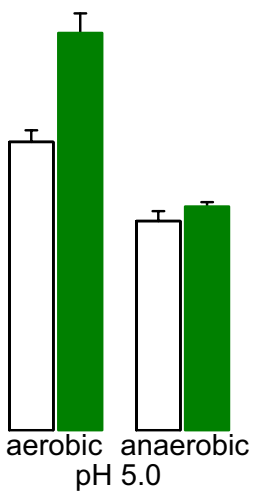

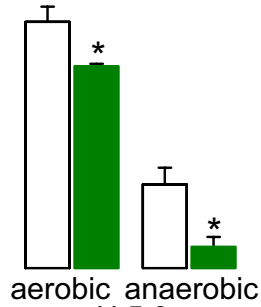

$\mathrm{pH} 5.0$

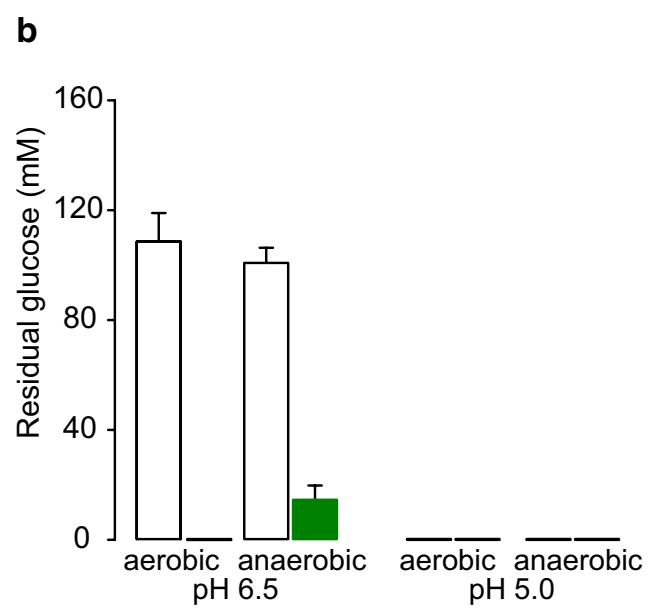

d

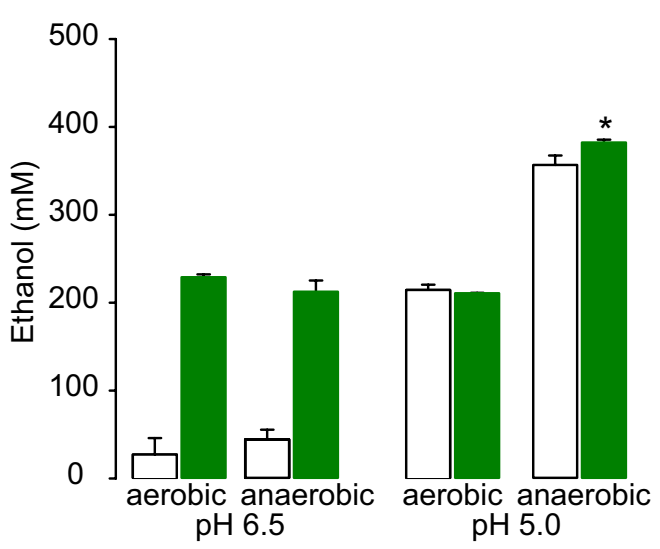

Fig. 7 Final growth and metabolites analysis after of $\mathrm{Y} 133$ and $\mathrm{Y} 133-\mathrm{ILL}$ in the presence of [BMIM]Cl. Growth (a), glucose and xylose consumption $(\mathbf{b}, \mathbf{c})$ and ethanol production (d) after $72 \mathrm{~h}$ of culture under aerobic and anaerobic conditions at pH 6.5 or pH 5.0. $(n=3$, except $n=2$ for $Y 133 \mathrm{pH}$ 6.5, Mean \pm S.E, $\left.{ }^{*} p<0.05\right)$

conditions, for instance for fatty acid biosynthesis [33]; thus, the PTK2 modification increases IIL tolerance and sugar utilization even during anaerobic fermentation at low pH (Fig. 7b).

IIL-based deconstruction methods hold significant promise for a feedstock-agnostic hydrolysates to feed lignocellulosic biorefineries. These IIL-based methods appear to be equivalently robust for deconstruction of both grasses and wood [40]. IILs in particular show promise for their ability to generate relatively pure sugar and lignin streams [6]. Thus, understanding the mechanisms of IIL toxicity in fermentative microbes is key to generating microbial strains engineered for IIL-based hydrolysates. Because removing residual IILs inevitably will confer an added cost in hydrolysate production, rational engineering of IIL-tolerant fermentative microbes can decrease the overall cost of IIL-based lignocellulosic biofuels and products.
Our results illustrate a general paradigm by which chemical genomics can enable rapid strain design in response to emerging bioconversion technologies. Both lignocellulose deconstruction technologies and the resulting landscape of fermentation inhibitors continue to evolve. Continued strain development will be necessary to keep pace with these new technologies and chemical stressors like IILs. Further, different industrial settings often necessitate use of different strain backgrounds; thus, it will be important that advantageous traits can be introduced rationally into diverse strain backgrounds. Our chemical genomics approach enables identification of such readily exploited traits for rational engineering. As our discovery system is based on S. cerevisiae, the primary lignocellulosic biorefinery microbe, the gene identified can be directly modified in other yeast strains to rapidly tailor proven strains for new hydrolysates. 


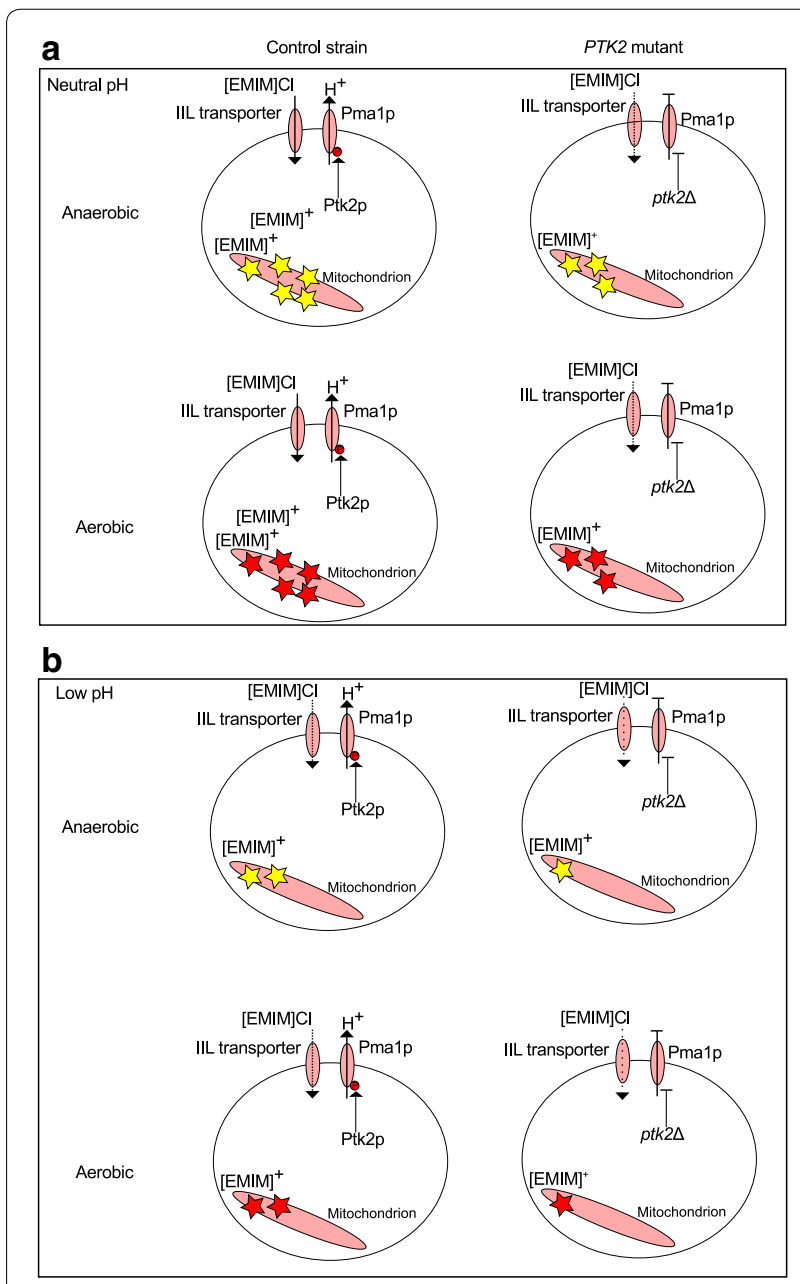

Fig. 8 A model for IIL toxicity and resistance. We propose the model of imidazolium IIL toxicity. In the presence of IILS at near neutral $\mathrm{pH}(\mathbf{a})$, cells pump out protons via Pma1p, which is coupled with import of the $[E M I M]^{+}$cation that results in hyperpolerization of the mitochondrial membrane. PTK2 activates Pma1p via phosphorlaytion. Deletion of PTK2 alleviates this by reducing Pma1p activity, and thus [EMIM]Cl influx. The effects of mitochondrial perturbation are more acute in aerobic conditions (red stars vs yellow stars), where mitochondria are more active. At lower pH (b), [EMIM]Cl import is lessened, similar to the polyamine cation spermine, which is alone regulated by PTK2

\section{Conclusions}

Chemical genomics-guided biodesign for strain engineering can also be applied to other bioproducts in addition to ethanol. Drugs, green chemicals, and nextgeneration fuels can be produced by yeast and other engineered microbes, and many of these end-products can be toxic to the biocatalyst microbe. The chemical genomics approach is a general way to define their mechanism of toxicity and discover means to engineer tolerance and improve their production. This approach is not limited to yeast; genome-wide mutant and overexpression collections exist in a number of industrially relevant microbes, including Escherichia coli and Zymomonas mobilis, making the chemical genomics approach translatable to these microbes as well.

\section{Additional files}

Additional file 1. Significantly responsive [EMIM]Cl deletion mutants.

Additional file 2. Significantly responsive protein abundance in [EMIM] $\mathrm{Cl}$.

Additional file 3. Fermentation profiles of $\mathrm{Y} 133$ and $\mathrm{Y} 133-\mathrm{IIL}$ in the presence of $1 \%[\mathrm{BMIM}] \mathrm{Cl}$ at $\mathrm{pH} 6.5$ and $\mathrm{pH} 5.0$, and either aerobic or anaerobic conditions $(n=3$, Mean \pm S.E, except $n=2$ for $Y 133 \mathrm{pH} 6.5$ anaerobic $72 \mathrm{~h}$ ).

Additional file 4. Final growth and metabolites analysis after of Y133 and Y133-IIL in the absence of [BMIM]Cl. Growth (a), glucose and xylose consumption $(\mathbf{b}, \mathbf{c})$, and ethanol production $(\mathbf{d})$ after $72 \mathrm{~h}$ of culture in the presence of $[\mathrm{BMIM}] \mathrm{Cl}$ at $\mathrm{pH} 6.5$ and $\mathrm{pH} 5.0$ in both aerobic and anaerobic conditions. $(n=3$, Mean \pm S.E).

\section{Abbreviations}

IL: ionic liquid; IIL: imidazolium ionic liquid; YPD: yeast extract peptone dextrose; DMSO: dimethyl sulfoxide.

\section{Authors' contributions}

QD, SB, LH, AH, JP performed experiments. TKS provided strains and edited the manuscript. RL and TKS designed experiments and edited the manuscript. CLM and SM developed software for analysis. SCL and CB created the specialized yeast deletion collection, the overexpression collection, and edited the manuscript. AH and JC performed proteomics and analysis. JP designed experiments, performed analysis, and wrote the manuscript. All authors read and approved the final manuscript.

\section{Author details}

${ }^{1}$ DOE Great Lakes Bioenergy Research Center, University of Wisconsin-Madison, Madison, WI 53726, USA. ${ }^{2}$ RIKEN Center for Sustainable Resource Science, Wako, Saitama, Japan. ${ }^{3}$ Department of Computer Science and Engineering, University of Minnesota-Twin Cities, Minneapolis, MN, USA. ${ }^{4}$ Terrence Donnelly Centre for Cellular and Biomolecular Research, University of Toronto, Toronto, ON, Canada. ${ }^{5}$ Biomolecular Chemistry, University of Wisconsin, Madison, WI, USA. ${ }^{6}$ Departments of Biochemistry and Bacteriology, University of Wisconsin, Madison, WI, USA.

\section{Authors' information}

$J P, Q D, S B, L H, S M, T K S, A H$ are scientists at the University of Wisconsin-Madison and the Great Lakes Bioenergy Research Center (GLBRC). SCL is a Foreign Postdoctoral Researcher at RIKEN. CLM is a Professor in the Department of Computer Science and Engineering at the University of Minnesota. CB is a Professor at the University of Toronto's Banting and Best Department of Medical Research. JC is a Professor in the Department of Chemistry at the University of Wisconsin-Madison. RL is a Professor of Biochemistry and Bacteriology at the University of Wisconsin-Madison.

\section{Acknowledgements}

This work was funded by the DOE Great Lakes Bioenergy Research Center (DOE BER Office of Science DE-FC02-07ER64494). CM is supported by grants from the National Institutes of Health (1R01HG005084-01A1, 1R01GM10497501, R01HG005853), a grant from the National Science Foundation (DBI 0953881). SL is supported by a RIKEN Foreign Postdoctoral fellowship. CM and CB are supported by the CIFAR Genetic Networks Program.

\section{Competing interests}

The authors declare that they have no competing interests. 
Received: 17 September 2015 Accepted: 8 January 2016 Published online: 20 January 2016

\section{References}

1. Piotrowski JS, Zhang Y, Bates DM, Keating DH, Sato TK, Ong IM, Landick R. Death by a thousand cuts: the challenges and diverse landscape of lignocellulosic hydrolysate inhibitors. Front Microbiol. 2014;5:90.

2. Palmqvist $E_{,}$Hahn-Hägerdal B. Fermentation of lignocellulosic hydrolysates. II: inhibitors and mechanisms of inhibition. Bioresour Technol. 2000;74:25-33.

3. Keating DH, Zhang Y, Ong IM, Mcllwain S, Morales EH, Grass JA, Tremaine M, Bothfeld W, Higbee A, Ulbrich A, Balloon AJ, Westphall MS, Aldrich J, Lipton MS, Kim J, Moskvin OV, Bukhman YV, Coon JJ, Kiley PJ, Bates DM, Landick R. Aromatic inhibitors derived from ammonia-pretreated lignocellulose hinder bacterial ethanologenesis by activating regulatory circuits controlling inhibitor efflux and detoxification. Microb Physiol Metab. 2014:5:402.

4. Almeida JR, Modig T, Petersson A, Hähn-Hägerdal B, Lidén G, GorwaGrauslund MF. Increased tolerance and conversion of inhibitors in lignocellulosic hydrolysates by Saccharomyces cerevisiae. J Chem Techno Biotechnol. 2007;82:340-9.

5. Luterbacher JS, Rand JM, Alonso DM, Han J, Youngquist JT, Maravelias CT, Pfleger BF, Dumesic JA. Nonenzymatic sugar production from biomass using biomass-derived $\gamma$-valerolactone. Science. 2014;343:277-80

6. Binder JB, Raines RT. Fermentable sugars by chemical hydrolysis of biomass. Proc Natl Acad Sci. 2010;107:4516-21.

7. Docherty KM, Charles F, Kulpa J. Toxicity and antimicrobial activity of imidazolium and pyridinium ionic liquids. Green Chem. 2005;7:185-9.

8. Ouellet M, Datta S, Dibble DC, Tamrakar PR, Benke PI, Li C, Singh S, Sale KL, Adams PD, Keasling JD, Simmons BA, Holmes BM, Mukhopadhyay A. Impact of ionic liquid pretreated plant biomass on Saccharomyces cerevisiae growth and biofuel production. Green Chem. 2011;13:2743.

9. Socha AM, Parthasarathi R, Shi J, Pattathil S, Whyte D, Bergeron M, George A, Tran K, Stavila V, Venkatachalam S, Hahn MG, Simmons BA, Singh S. Efficient biomass pretreatment using ionic liquids derived from lignin and hemicellulose. Proc Natl Acad Sci. 2014;111:E3587-95.

10. Li C, Tanjore D, He W, Wong J, Gardner JL, Sale KL, Simmons BA, Singh S. Scale-up and evaluation of high solid ionic liquid pretreatment and enzymatic hydrolysis of switchgrass. Biotechnol Biofuels. 2013;6:1-14.

11. Underkofler KA, Teixeira RE, Pietsch SA, Knapp KG, Raines RT. Separation of lignin from corn stover hydrolysate with quantitative recovery of ionic liquid. ACS Sustain Chem Eng. 2015;3:606-13.

12. Mehmood N, Husson E, Jacquard C, Wewetzer S, Büchs J, Sarazin C, Gosselin I. Impact of two ionic liquids, 1-ethyl-3-methylimidazolium acetate and 1-ethyl-3-methylimidazolium methylphosphonate, on Saccharomyces cerevisiae: metabolic, physiologic, and morphological investigations. Biotechnol Biofuels. 2015;8:1-14

13. Sato TK, Liu T, Parreiras LS, Williams DL, Wohlbach DJ, Bice BD, Ong IS, Breuer RJ, Qin L, Busalacchi D, Deshpande S, Daum C, Gasch AP, Hodge DB. Harnessing genetic diversity in Saccharomyces cerevisiae for improved fermentation of xylose in hydrolysates of alkaline hydrogen peroxide pretreated biomass. Appl Environ Microbiol. 2014;80(2):540-54.

14. Parreiras LS, Breuer RJ, Avanasi Narasimhan R, Higbee AJ, La Reau A, Tremaine M, Qin L, Willis LB, Bice BD, Bonfert BL, Pinhancos RC, Balloon AJ, Uppugundla N, Liu T, Li C, Tanjore D, Ong IM, Li H, Pohlmann EL, Serate J, Withers ST, Simmons BA, Hodge DB, Westphall MS, Coon JJ, Dale BE, Balan $\checkmark$, Keating DH, Zhang Y, Landick R, et al. Engineering and two-stage evolution of a lignocellulosic hydrolysate-tolerant Saccharomyces cerevisiae strain for anaerobic fermentation of xylose from AFEX pretreated corn stover. PLoS One. 2014;9:e107499.

15. Skerker JM, Leon D, Price MN, Mar JS, Tarjan DR, Wetmore KM, Deutschbauer AM, Baumohl JK, Bauer S, Ibáñez AB, Mitchell VD, Wu CH, Hu P, Hazen T, Arkin AP. Dissecting a complex chemical stress: chemogenomic profiling of plant hydrolysates. Mol Syst Biol. 2013;9:674.

16. Piotrowski JS, Simpkins SW, Li SC, Deshpande R, Mcllwain SJ, Ong IM, Myers CL, Boone C, Andersen RJ. Chemical genomic profiling via barcode sequencing to predict compound mode of action. Methods Mol Biol. 2015;1263:299-318
17. Parsons A, Lopez A, Givoni I, Williams D, Gray C, Porter J, Chua G, Sopko R, Brost R, Ho C. Exploring the mode-of-action of bioactive compounds by chemical-genetic profiling in yeast. Cell. 2006;126:611-25.

18. Fung SY, Sofiyev V, Schneiderman J, Hirschfeld AF, Victor RE, Woods K, Piotrowski JS, Deshpande R, Li SC, de Voogd NJ, Myers CL, Boone C, Andersen RJ, Turvey SE. Unbiased screening of marine sponge extracts for anti-inflammatory agents combined with chemical genomics identifies girolline as an inhibitor of protein synthesis. ACS Chem Biol. 2014;9(1):247-57.

19. Andrusiak K. Adapting S. cerevisiae Chemical genomics for identifying the modes of action of natural compounds. Thesis. 2012

20. Smith AM, Heisler LE, Mellor J, Kaper F, Thompson MJ, Chee M, Roth FP, Giaever G, Nislow C. Quantitative phenotyping via deep barcode sequencing. Genome Res. 2009;19:1836-42.

21. Robinson DG, Chen W, Storey JD, Gresham D. Design and analysis of barseq experiments. 2014;G3 (Bethesda)(4):11-8.

22. Robinson MD, McCarthy DJ, Smyth GK. edgeR: a bioconductor package for differential expression analysis of digital gene expression data. Bioinforma Oxf Engl. 2010;26:139-40.

23. Boyle El, Weng S, Gollub J, Jin H, Botstein D, Cherry JM, Sherlock G. GO:Termfinder-open source software for accessing gene ontology information and finding significantly enriched gene ontology terms associated with a list of genes. Bioinformatics. 2004;20:3710-5.

24. Winzeler EA, Shoemaker DD, Astromoff A, Liang H, Anderson $K$, Andre B, Bangham R, Benito R, Boeke JD, Bussey H, Chu AM, Connelly C, Davis K, Dietrich F, Dow SW, El Bakkoury M, Foury F, Friend SH, Gentalen E, Giaever G, Hegemann JH, Jones T, Laub M, Liao H, Liebundguth N, Lockhart DJ, Lucau-Danila A, Lussier M, M'Rabet N, Menard P, et al. Functional characterization of the S. cerevisiae genome by gene deletion and parallel analysis. Science. 1999;285:901-6.

25. Magtanong L, Ho CH, Barker SL, Jiao W, Baryshnikova A, Bahr S, Smith AM, Heisler LE, Choy JS, Kuzmin E, Andrusiak K, Kobylianski A, Li Z, Costanzo M, Basrai MA, Giaever G, Nislow C, Andrews B, Boone C. Dosage suppression genetic interaction networks enhance functional wiring diagrams of the cell. Nat Biotechnol. 2011;29:505-11.

26. Gietz RD, Schiestl RH. High-efficiency yeast transformation using the LiAc/SS carrier DNA/PEG method. Nat Protoc. 2007;2:31-4.

27. Erez O, Kahana C. Deletions of SKY1 or PTK2 in the Saccharomyces cerevisiae trk1Deltatrk2Delta mutant cells exert dual effect on ion homeostasis. Biochem Biophys Res Commun. 2002;295:1142-9.

28. Kaouass M, Audette M, Ramotar D, Verma S, De Montigny D, Gamache I, Torossian K, Poulin R. The STK2 gene, which encodes a putative Ser/Thr protein kinase, is required for high-affinity spermidine transport in Saccharomyces cerevisiae. Mol Cell Biol. 1997;17:2994-3004.

29. Erez O, Kahana C. Screening for modulators of spermine tolerance identifies Sky1, the SR protein kinase of saccharomyces cerevisiae, as a regulator of polyamine transport and ion homeostasis. Mol Cell Biol. 2001;21:175-84.

30. Moore C, Pressman BC. Mechanism of action of valinomycin on mitochondria. Biochem Biophys Res Commun. 1964;15:562-7.

31. Hebert AS, Richards AL, Bailey DJ, Ulbrich A, Coughlin EE, Westphall MS, Coon JJ. The one hour yeast proteome. Mol Cell Proteomics. 2014;13:339-47.

32. Pereira C, Silva RD, Saraiva L, Johansson B, Sousa MJ, Côrte-Real M. Mitochondria-dependent apoptosis in yeast. Biochim Biophys Acta BBA-Mol Cell Res. 2008;1783:1286-302.

33. Reiner S, Micolod D, Zellnig G, Schneiter R. A genomewide screen reveals a role of mitochondria in anaerobic uptake of sterols in yeast. Mol Biol Cell. 2006;17:90-103.

34. Fiedler D, Braberg H, Mehta M, Chechik G, Cagney G, Mukherjee P, Silva AC, Shales M, Collins SR, van Wageningen S, Kemmeren P, Holstege FCP, Weissman JS, Keogh M-C, Koller D, Shokat KM, Krogan NJ. Functional organization of the S. cerevisiae phosphorylation network. Cell. 2009;136:952-63.

35. Sharifpoor S, van Dyk D, Costanzo M, Baryshnikova A, Friesen H, Douglas AC, Youn J-Y, VanderSluis B, Myers CL, Papp B, Boone C, Andrews BJ. Functional wiring of the yeast kinome revealed by global analysis of genetic network motifs. Genome Res. 2012;22:791-801.

36. Demeke MM, Dietz H, Li Y, Foulquié-Moreno MR, Mutturi S, Deprez S, Abt TD, Bonini BM, Liden G, Dumortier F, Verplaetse A, Boles E, Thevelein JM. Development of a D-xylose fermenting and inhibitor tolerant industrial Saccharomyces cerevisiae strain with high performance in lignocellulose 
hydrolysates using metabolic and evolutionary engineering. Biotechnol Biofuels. 2013;6:89.

37. Eliasson A, Christensson C, Wahlbom CF, Hahn-Hägerdal B. Anaerobic Xylose fermentation by recombinant Saccharomyces cerevisiae carrying XYL1, XYL2, and XKS1 in mineral medium chemostat cultures. Appl Environ Microbiol. 2000;66:3381-6.

38. Goossens A, de la Fuente N, Forment J, Serrano R, Portillo F. Regulation of yeast $\mathrm{H}+$-ATPase by protein kinases belonging to a family dedicated to activation of plasma membrane transporters. Mol Cell Biol. 2000;20:7654-61.
39. Uemura $\mathrm{T}$, Tachihara $\mathrm{K}$, Tomitori $\mathrm{H}$, Kashiwagi $\mathrm{K}$, Igarashi $\mathrm{K}$. Characteristic of the polyamine transporter TPO1 and regulation of its activity and celIular localization by phosphorylation. J Biol Chem. 2005;280:9646-52.

40. Fort DA, Remsing RC, Swatloski RP, Moyna P, Moyna G, Rogers RD. Can ionic liquids dissolve wood? processing and analysis of lignocellulosic materials with 1-n-butyl-3-methylimidazolium chloride. Green Chem. 2007:9:63-9.
Submit your next manuscript to BioMed Central and we will help you at every step:

- We accept pre-submission inquiries

- Our selector tool helps you to find the most relevant journal

- We provide round the clock customer support

- Convenient online submission

- Thorough peer review

- Inclusion in PubMed and all major indexing services

- Maximum visibility for your research

Submit your manuscript at www.biomedcentral.com/submit
() Biomed Central 